\title{
Tissue Engineering Models of Human Digits: Effect of Periosteum on Growth Plate Cartilage Development
}

\author{
William J. Landis ${ }^{\mathrm{a}}$ Robin Jacquet ${ }^{\mathrm{a}}$ Elizabeth Lowder ${ }^{\mathrm{a}}$ Mitsuhiro Enjo ${ }^{\mathrm{a}, \mathrm{b}}$ \\ Yoshitaka Wada ${ }^{a, b}$ Noritaka Isogai ${ }^{a, b}$ \\ ${ }^{a}$ Department of Integrative Medical Sciences, Northeastern Ohio Universities Colleges of Medicine and Pharmacy, \\ Rootstown, Ohio, USA; ${ }^{b}$ Department of Plastic and Reconstructive Surgery, Kinki University Medical School, Osaka, \\ Japan
}

\section{Key Words}

Tissue engineering $\cdot$ Growth plate cartilage $\cdot$ Periosteum • Development • Bone

\begin{abstract}
Tissue-engineered middle phalanx constructs of human digits were investigated to determine whether periosteum wrapped partly about model midshafts mediated cartilage growth plate formation. Models were fabricated by suturing ends of polymer midshafts in a human middle phalanx shape with polymer sheets seeded with heterogeneous chondrocyte populations from bovine articular cartilage. Half of each midshaft length was wrapped with bovine periosteum. Constructs were cultured, implanted in nude mice for up to 20 weeks, harvested and treated histologically to assess morphology and cartilage proteoglycans. After 20 weeks of implantation, chondrocyte-seeded sheets adjacent to periosteum-wrapped midshaft halves established cartilage growth plates resembling normal tissue in vivo. Sheets adjacent to midshafts without periosteum had disorganized cells and no plate formation. Proteoglycans were present at both midshaft ends. Periosteum appears to guide chondrocytes toward growth plate cartilage organization and tissue engineering provides means for carefully examining construct development of this tissue.

Copyright $\odot 2008$ S. Karger AG, Basel
\end{abstract}

\section{Introduction}

The design and development of tissue-engineered models of the human distal and middle phalanx have been undertaken in recent years and various aspects of their resulting formation have been published [Isogai et al., 1999; Isogai and Landis, 2001; Chubinskaya et al., 2004; Landis et al., 2005]. The models have demonstrated the use of bovine cells on different biodegradable polymer scaffolds to form constructs that recapitulate normal bovine bone, cartilage and tendon in vivo in several important features, including the expression of numerous genes and secretion of corresponding proteins and the presence of a growth plate at the end(s) of the model midshafts [Isogai et al., 1999; Isogai and Landis, 2001; Chubinskaya et al., 2004; Landis et al., 2005]. It is not clear how growth plate cartilage forms in the tissue-engineered specimens, but assessing this tissue at several time points over its development has shown the presence of resting, proliferating, maturing and hypertrophic cells, organization of ma-

Abbreviation used in this paper

PGA polyglycolic acid

Dr. William J. Landis

Department of Integrative Medical Sciences, Northeastern Ohio Universities Colleges of Medicine and Pharmacy, Room C-126, 4209 State Route 44 Rootstown, OH 44272 (USA)

Tel. +1 330325 6685, Fax +1 330325 5925, E-Mail wjl@neoucom.edu 
turing and hypertrophic cells in columnar fashion characterizing normal tissue in vivo, expression of type II and $\mathrm{X}$ collagen, aggrecan, osteopontin, osteocalcin, bone sialoprotein and other known cartilage genes, presence of proteoglycans in the cartilage matrices, and appearance of mineral in tissue regions deep to the hypertrophic zones [Isogai et al., 1999; Isogai and Landis, 2001; Chubinskaya et al., 2004; Landis et al., 2005]. An additional factor of interest in the development of the presumptive growth plate cartilage of the constructs is whether periosteum exerts effects on growth plate formation. This concept has been suggested in part by experimental evidence from cell and organ culture studies [Di Nino et al., 2002; Di Nino and Linsenmayer, 2003; Crochiere et al., 2008]. Thus, the present work examined the hypothesis that periosteal tissue wrapped in part about the midshaft scaffolds of the tissue-engineered models of the human middle phalanges mediates adjacent cartilage growth plate formation. The results of this investigation indicate that periosteum may guide changes in heterogeneous chondrocyte populations toward a growth plate cartilage organization. The models thereby provide a means to examine such changes more completely in regard to gene expression of cartilage and periosteal cells, protein secretion and phalanx structure as an approach to understanding the features of the present tissue-engineered human phalanx models as well as those of growth plate formation in vertebrates in general.

\section{Methods}

Tissue-engineered human middle phalanx models $(n=6)$ were designed following methodology described previously utilizing articular cartilage and periosteum [Isogai et al., 1999; Isogai and Landis, 2001]. Tissues were obtained from shoulders or long bones from freshly sacrificed 1- to 6-month-old calves, packed on ice and transported to the laboratory. Cartilage was treated with collagenase and chondrocytes were isolated, filtered and concentrated [Isogai et al., 1999; Isogai and Landis, 2001]. Periosteum was removed surgically in thin strips approximately $1 \mathrm{~cm}$ wide and $2 \mathrm{~cm}$ long. Constructs were fabricated by suturing the ends of a polycaprolactone/poly-L-lactic acid (50:50) midshaft (approx. $1.5 \mathrm{~cm}$ in length and $0.5 \mathrm{~cm}$ in width) in a human middle phalanx shape with a polyglycolic acid sheet (PGA; approx. $1 \times 1 \times 0.2 \mathrm{~cm}$ in length, width and thickness). Prior to suturing, each PGA sheet was seeded with the heterogeneous population of chondrocytes isolated and concentrated $\left(1.5 \times 10^{8}\right.$ cells $\left./ \mathrm{ml}\right)$ from normal bovine articular cartilage [Isogai et al., 1999; Isogai and Landis, 2001]. Each midshaft was wrapped over half its length with a single strip of the normal bovine periosteum, the cambium layer of the tissue being placed in contact with the midshaft scaffold [Isogai et al., 1999; Isogai and Landis, 2001]. The remaining half midshaft length was left uncovered. Constructs were cultured for 7-10 days in DMEM/ Ham's F12 medium (1:1) supplemented with 10\% FBS, L-glutamine, ascorbate and an antibiotic/antimycotic mixture [Isogai and Landis, 2001] and then implanted in the dorsum of 4- to 6-week-old male nude mice for up to 20 weeks. Harvested implants were fixed in neutral buffered formalin, paraffin-embedded and initially examined by X-ray radiography to assess possible mineral formation. They were then sectioned longitudinally at $7-\mu \mathrm{m}$ thickness and stained with toluidine blue and Safranin-O red to determine morphology and cartilage proteoglycan presence, respectively.

\section{Results}

After 20 weeks of implantation, engineered human middle phalanx models were found to have glistening, firm and well defined cartilage on both ends of their individual midshaft regions (fig. 1). The portion of midshaft covered with periosteum consisted of essentially clear tissue having a few red-colored areas over its surface indicative of vascular formation. The midshaft region left unwrapped was notably reddened and vascularized (fig. 1). X-ray radiography revealed marked mineral deposition within the midshafts of the models only where periosteum had been placed and sutured (fig. 2). No mineral formation was detectable in the cartilage regions at the ends of the models (fig. 2). Following their sectioning and staining with Safranin-O, proteoglycan presence was observed in the cartilage at either end of the constructs. Enlargement of cartilage zones showed that chondrocyte-seeded PGA sheets adjacent to the half of model midshafts wrapped with periosteum established a growth plate composed of defined regions of resting, proliferating, maturing and hypertrophic cells resembling normal tissue in vivo (fig. 3). Chondrocytes comprising lower portions of these plates were organized into columns and deepest regions were found with mixed spicules undergoing endochondral replacement to bone. Vascular invasion in the same deep regions of construct cartilage occurred through host mouse intervention [Chubinskaya et al., 2004; Landis et al., 2005]. Over identical implantation times, chondrocyte-seeded PGA sheets adjacent to the half of the same model midshafts left uncovered by periosteum had disorganized cells and no growth plate formation or mineralization (fig. 4).

\section{Discussion}

The tissue engineering design of middle phalanx models of human digits previously demonstrated that complete covering of midshaft scaffolds resulted in cartilage growth plate formation at both ends of these constructs 


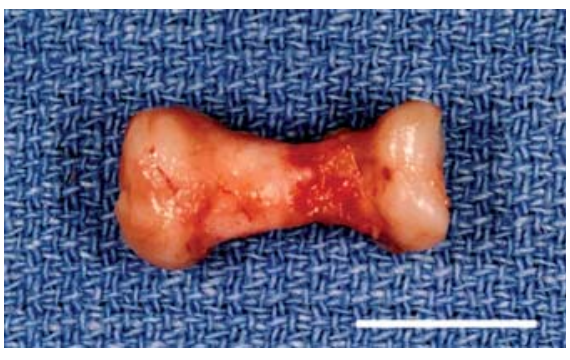

Fig. 1. A tissue-engineered human middle phalanx retrieved 20 weeks after implantation in a nude mouse. Periosteum initially covered the left half of the scaffold midshaft. Scale bar $=1 \mathrm{~cm}$.

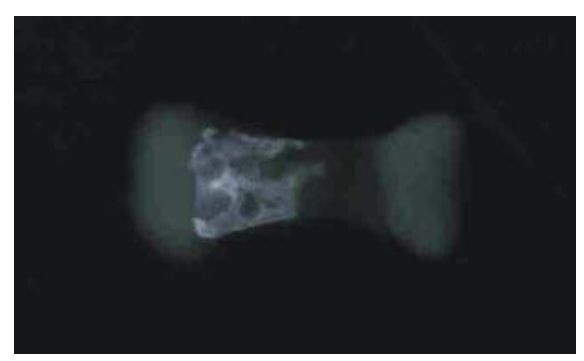

Fig. 2. An X-ray radiograph of the identical construct shown in figure 1. Mineral deposition has occurred only within the construct region that was wrapped with a narrow strip of periosteum. Differences in the degree of mineralization contribute to some variation in X-ray density.

[Isogai et al., 1999; Isogai and Landis, 2001]. Wrapping the midshaft over only half its length in the models has provided a means for directly comparing the putative effects of periosteum on cartilage development within the same construct.

In this context, results are consistent and reproducible: While both ends of cartilage in middle phalanx models maintain viable chondrocytes that secrete matrices rich in proteoglycans, the presence of a periosteum leads the heterogeneous chondrocyte populations toward cell organization characteristic of growth plate cartilage. Deep regions of such plates calcify. In that region of the constructs absent of periosteum, no organized plate appears and there is no subsequent cartilage calcification. These results support the possibility that periosteal tissue mediates growth plate cartilage formation, perhaps by synthesis and secretion of growth factors and other proteins that provide diffusion-limited regulation and control of neighboring cartilage. The tissue-engineered phalanx models thereby represent a novel means to examine the numerous observed changes noted above in terms of

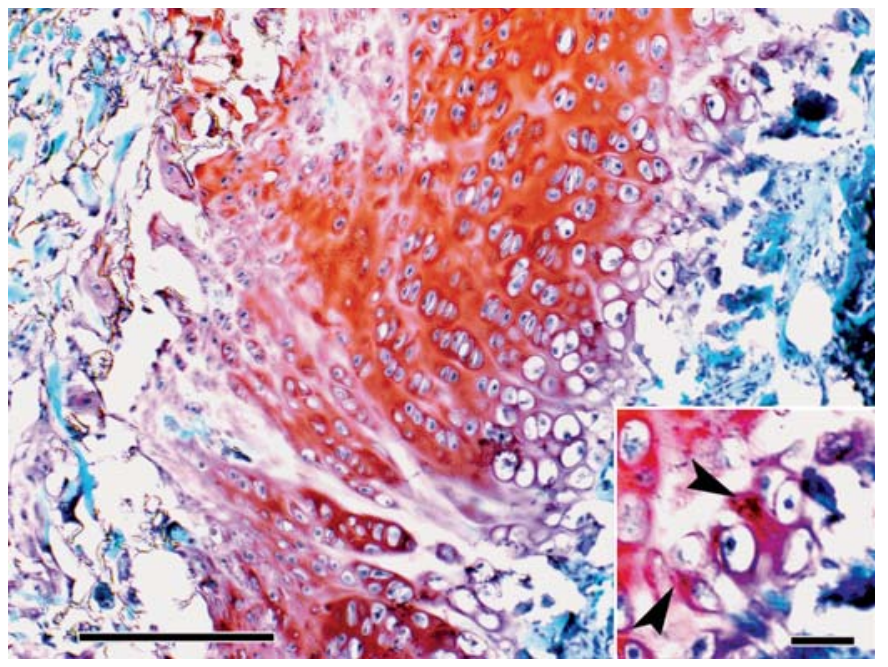

Fig. 3. Formation of a rudimentary growth plate in a middle phalanx model implanted for 20 weeks in a nude mouse. The region comprises a portion of the construct midshaft half covered with periosteum. The orientation of the section illustrated is approximately perpendicular to the long axis of the phalanx shown in figure 1. Cells exhibit different phenotypes, and proliferating and hypertrophic chondrocytes are clearly organized into columns like normal growth plates in vivo. Proteoglycans are evident on Safranin-O staining and deep cartilage regions are calcified. Scale bar $=150 \mu \mathrm{m}$. The inset shows an enlargement of a portion of the upper right corner (arrowheads point to mineral deposition). Scale bar $=50 \mu \mathrm{m}$.

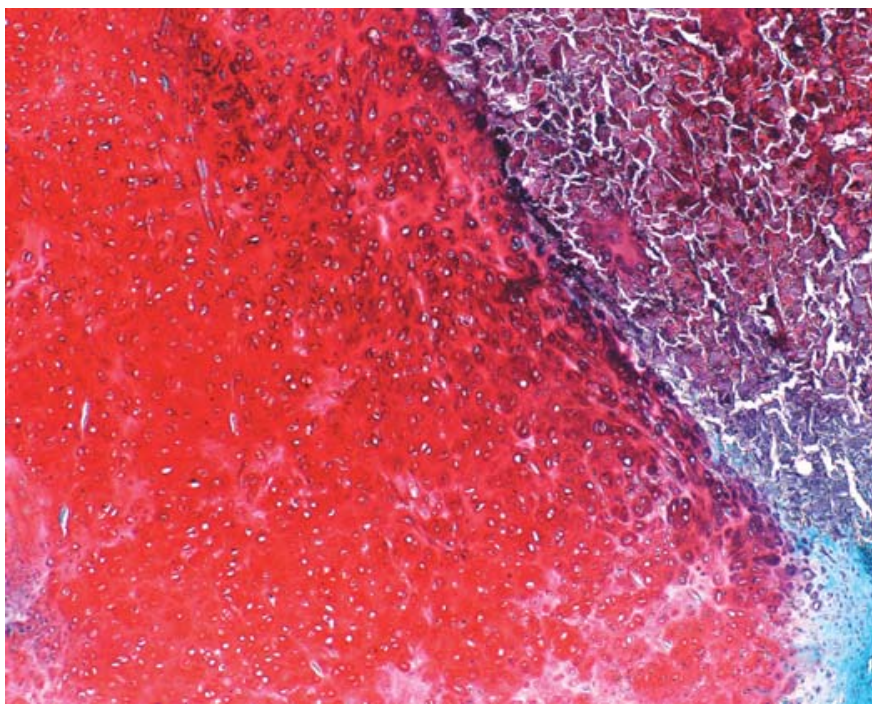

Fig. 4. The cartilaginous portion of the identical 20 -week implanted construct shown in figure 3 but comprising the midshaft half that was not wrapped with periosteum. Orientation of this section is as noted in figure 3. Chondrocytes secrete proteoglycans, but the cells, of somewhat similar phenotype, remain disorganized. Deeper cell regions are not calcified. The section was stained with Safranin-O. Enlargement is as in figure 3. 
gene expression of cartilage and periosteal cells, protein secretion, matrix formation and mineralization as an approach to understanding more completely the development, composition and structure of these constructs. Initial unpublished data obtained by laser capture microdissection and quantitative RT-PCR [Jacquet et al., 2005] indicate gene expression of (bovine) type II collagen, aggrecan, osteopontin, osteocalcin and bone sialoprotein in the developing cartilaginous growth plates of the constructs, results consistent with normal growth plates from long bones [Ganss et al., 1999; Sodek et al., 2000; Boskey, 2005]. These findings are important in further expansion and characterization of the models and in establishing their potential correlation with normal human digits. On the other hand, there are several aspects of the normal development of a growth plate cartilage in long bones that remain poorly defined. In addition to the potential role of the periosteum and perichondrium in limb formation and lengthening, precise interactions of signaling genes such as Indian hedgehog, PTHrP and TGF$\beta$ [Ballock et al., 2003; Eames et al., 2003; Kronenberg et al., 2006] in growth plate cartilage and modulation of secreted proteins as well as growth plate biochemistry and structure are also not fully known. More thorough analyses, then, of the tissue-engineered model constructs described here will undoubtedly provide greater insight and knowledge of the normal mechanisms, events and processes in vivo of growth plate and bone formation in vertebrate tissues.

\section{Acknowledgments}

This work was supported by grant AR41452 from the National Institutes of Health (to W.J.L.).

\section{References}

Ballock, R.T., R.J. O'Keefe (2003) The biology of the growth plate. J Bone Joint Surg 85: $715-$ 726.

Boskey, A.L. (2005) The organic and inorganic matrices; in Hollinger, J.O., H.C. Kleinschmidt (eds): Bone Tissue Engineering. Boca Raton, CRC Press, pp 91-124.

-Chubinskaya, S., R. Jacquet, N. Isogai, S. Asamura, W.J. Landis (2004) Characterization of the cellular origin of a tissue-engineered human phalanx model by in situ hybridization. Tissue Eng 10: 1204-1213.

Crochiere, M.L., J.K. Kubilus, T.F. Linsenmayer (2008) Perichondrial-mediated TGF- $\beta$ regulation of cartilage growth in avian long bone development. Int J Dev Biol 52: 63-70.
Di Nino, D.L., M.L. Crochiere, T.F. Linsenmayer (2002) Multiple mechanisms of perichondrial regulation of cartilage growth. Dev Dyn 225: 250-259.

Di Nino, D.L., T.F. Linsenmayer (2003) Positive regulation of endochondral cartilage growth by perichondrial and periosteal calcitonin. Endrocrinology 144: 1979-1983.

Eames, B.F., L. de la Fuente, J.A. Helms (2003) Molecular ontogeny of the skeleton. Birth Defects Res C Embryo Today 69: 93-101.

Ganss, B., R.H. Kim, J. Sodek (1999) Bone sialoprotein. Crit Rev Oral Biol Med 10: 79-98.

Isogai, N., W.J. Landis, T.H. Kim, L.C. Gerstenfeld, J. Upton, J.P. Vacanti (1999) Formation of phalanges and small joints by tissue engineering. J Bone Joint Surg 81-A: 306-316.

Isogai, N., W.J. Landis (2001) Phalanges and Small Joints; in Atala, A., R. Lanza (eds): Methods of Tissue Engineering. San Diego, Academic Press, pp 1041-1047.
Jacquet, R., J. Hillyer, W.J. Landis (2005) Analysis of connective tissues by laser capture microdissection and reverse transcriptasepolymerase chain reaction. Anal Biochem 337: 22-34.

Kronenberg, H.M. (2006) PTHrP and skeletal development. Ann NY Acad Sci 1068: 1-13.

Landis, W.J., R. Jacquet, J. Hillyer, E. Lowder, A. Yanke, L. Siperko, S. Asamura, H. Kusuhara, M. Enjo, S. Chubinskaya, K. Potter, N. Isogai (2005) Design and assessment of a tissue-engineered model of human phalanges and a small joint. Orthod Craniofac Res 8: $303-$ 312 .

Sodek, J., B. Ganss, M.D. McKee (2000) Osteopontin. Crit Rev Oral Biol Med 11: 279-303. 